\title{
An experimental test of the effects of online and face-to-face feedback on self-esteem
}

\author{
Helen G. M. Vossen ${ }^{1}$, Maria Koutamanis ${ }^{2}$, \& Joseph B. Walther ${ }^{3}$ \\ ${ }^{1}$ Department of Child and Adolescent Studies, Utrecht University, Utrecht, The Netherlands \\ ${ }^{2}$ Amsterdam School of Communication Research ASCoR, University of Amsterdam, Amsterdam, The Netherlands \\ ${ }^{3}$ Department of Communication and the Center for Information Technology and Society, University of California, Santa \\ Barbara, CA, United States
}

\begin{abstract}
This study investigated the effect of receiving confirming vs. disconfirming feedback to individuals' self-disclosure on their self-esteem, the role of giving reciprocal feedback in this relationship, and how these effects differ between online and face-to-face communication. Using a two (communication mode: online vs. face-to-face) by two (feedback valence: confirming vs. disconfirming) between-subjects experiment, we found that feedback had a significant indirect effect on self-esteem, through the receiver's reciprocal feedback. This indirect effect of feedback differed in online communication from offline: In online communication, participants reciprocated negative feedback when they received it, more than in face-to-face communication. The reciprocal feedback enhanced their self-esteem in online communication, but not in face-to-face communication. Although people tend to respond more negatively to negative comments in online conversations, the process, overall, boosts rather than hinders their self-esteem.
\end{abstract}

Keywords: Online communication; feedback; self-esteem; reciprocal feedback, online self-disclosure

\section{Introduction}

Recent research on computer-mediated communication has consistently demonstrated the importance of selfdisclosure in online interaction. Disclosure has a significant role in online impression formation (e.g., Antheunis, Valkenburg, \& Peter, 2007), the development of intimacy (Bazarova, 2012), and friendship quality (Valkenburg \& Peter, 2009a). Less, however, is known about the communication dynamics surrounding self-disclosure in online interaction, that is, the responses that people receive to their online self-disclosure. This gap is remarkable because reciprocal interactions over time are crucial for how online communication develops (Walther, 1996). Self-disclosure involves risk and vulnerability, theorists suggest (Jourard, 1964). Therefore, social responses to self-disclosure should provide important influences on the individual and social outcomes of which disclosure is a part. The present study, therefore, focuses on how feedback on self-disclosure affects online communication processes and their outcomes.

One important outcome of feedback on online self-disclosure is self-esteem. Developing a stable sense of selfworth is an important developmental task for young people and highly predictive of psychological well-being (Baumeister, Campbell, Krueger, \& Vohs, 2003; Sowislo \& Orth, 2013). Self-esteem is largely formed through interactions with peers (Harter, 2012a), which nowadays often take place online. Therefor it is surprising that we still know little about the role of feedback to self-disclosure in online communication and its effects on people's self-esteem. The few studies that have investigated the effects of online feedback have shown that receiving confirming feedback augments effects of selective self-presentation on how people perceive themselves 
(Walther, 2011), and that peer feedback in social media is related to the recipient's self-esteem (Thomaes et al., 2010; Valkenburg, Peter, \& Schouten, 2006). However, the influence that feedback to one's online self-disclosure may exert on self-esteem has hardly been studied. The first aim of the current study was to fill this gap.

A second gap in our knowledge concerns how individuals respond to feedback to their self-disclosure, and how their responses also affect their self-esteem. The responses to feedback may be equally, or even more, important than the initial feedback itself for how online self-disclosure affects self-esteem. After all, people's responses to information from their communication partner form an important influence in the development of conversations (Snyder, Tanke, \& Berscheid, 1977). To our knowledge, previous research has yet to investigate people's overt responses to the feedback they receive on their self-disclosure. Without such knowledge, research cannot explain why feedback to online self-disclosure may affect people's self-esteem. Investigating this was the second aim of the present study.

Previous research suggests that characteristics of online communication, such as the reduced audiovisual cues, enhance the influence of receiving feedback on self-disclosure in online communication compared to face-toface communication (Walther, 1996). Although this position is reasonable, previous studies have focused only on online feedback without comparison to face-to-face feedback, which may lead to inflated views of findings within online environments (Walther, 2011). It is critical to assess whether this impact is attributable to online communication in comparison to face-to-face communication. The third and final aim of this study, therefore, is to investigate whether the effects of feedback and responding to feedback (i.e. reciprocal feedback) on selfesteem differ between online communication and face-to-face communication. Investigating how both receiving and providing online feedback influences one's self-esteem is important, given the increasing number of online platforms on which people can self-disclose and the increasing opportunities to provide feedback on these new online platforms.

\section{The Effect of Online Feedback on Self-Esteem}

In the literature, feedback is conceptualized in different ways. According to Cissna and Sieburg (1981), confirming responses from others recognize and validate the discloser's sense of self. Disconfirming responses reject the message and deny the other's experience, or withdraws involvement from the discloser. Reis and Shaver's (1988) interpersonal process model of intimacy argues that a partner's confirming response to self-disclosure makes the discloser feel acknowledged and understood, whereas a disconfirming response undermines a discloser's sense of self. The current focus on feedback as confirming or disconfirming evaluative comments highlights how such comments can be particularly important to a receiver's self-esteem (e.g., Thomaes et al., 2010; Valkenburg et al., 2006).

Despite its important role in online communication, online feedback has received relatively little attention in research to date, especially in relation to self-esteem. Only five studies have dealt with the consequences of receiving online feedback on self-esteem. A survey study among Dutch adolescents found that individuals who frequently used social network sites received mainly positive feedback, which, in turn, was related positively with their social self-esteem and well-being (Valkenburg et al., 2006). These results were later replicated in a more recent study by the same first author (Valkenburg, Koutamanis, \& Vossen, 2017). A Japanese survey study found that positive feedback on teenagers' blogs increased a concept close to self-esteem, that is, satisfaction with themselves and feelings of acceptance, whereas negative feedback decreased satisfaction and feelings of acceptance (Miura \& Yamashita, 2007). In addition, a recent survey study by Greitemeyer, Mügge, and Bollermann (2014) confirmed that positive online feedback to Facebook posts related to higher self-esteem, whereas negative online feedback related to lower self-esteem. Finally, the relation between feedback valence and self-esteem was also confirmed in an experimental study (Thomaes et al., 2010). Consistent with the results of these studies, we hypothesize that receiving confirming feedback to one's self-disclosure leads to higher selfesteem compared to receiving disconfirming feedback ( $\mathrm{H} 1 \mathrm{a})$.

Feedback in online vs. face-to-face communication. The above-mentioned findings on the effects of receiving online feedback on self-esteem are in line with findings of studies investigating the effects of receiving face-toface feedback on self-esteem. These studies also show that peer approval (i.e. confirming feedback) is positively related to self-esteem, whereas peer rejection (i.e. disconfirming feedback) is negatively related to peer feedback 
(Gruenenfelder-Steiger, Harris, \& Fend, 2016; Harter, 2012a; Srivastava \& Beer, 2005). Yet, there is also reason to believe that the effects of online versus face-to-face feedback might be different. The hyperpersonal model of computer-mediated communication (Walther, 1996) specifies how online interactions can exceed the potency of face-to-face interactions. According to this model, the editability of messages and the reduced audiovisual cues of online communication promote selective and desirable self-presentation and communication. In response to these reduced cues, people typically fill in the blanks based on the information they receive. When initial information is favorable, they tend to extrapolate impressions and affective reactions in a positive way, creating idealized impressions of their online communication partners and their relationships. This theoretical model is supported by empirical studies demonstrating that online communication has a more substantial effect on interpersonal impressions than face-to-face or telephone communication (Carr \& Foreman, 2016; Jiang, Bazarova, \& Hancock, 2011; Walther, DeAndrea, \& Tong, 2010). And specifically related to self-esteem, a study using experienced sampling method demonstrated that text-based communication was more strongly related to self-esteem than face-to-face communication (Gonzales, 2014). Feedback also has a specific role in this model as it can reinforce and extend these idealized impressions of, and relationships with, online communication partners. Given the well-established dynamic of behavioral confirmation (Snyder et al., 1977), people eventually confirm these idealized impressions of their online communication partners by actually behaving in line with the positive impressions they have of their partners and their relationship with them (Walther, Kashian, Jang, \& Shin, 2016).

Although the hyperpersonal communication model (Walther, 1996) focuses on the intensification of positive interactions and effects, its basic propositions are also applicable to negative online interactions. In the same way in which positive cues in online communication are theorized to enhance the interpretation of an online interaction as positive, negative cues may accordingly intensify the interpretation of an online interaction as negative. Moreover, misinterpretation of messages caused by the reduced cues in online communication has been suggested to induce negative communication, such as flaming (Kruger, Epley, Parker, \& Ng, 2005).

Thus, theory and previous studies suggest that positive cues, such as confirming feedback, are likely to be interpreted more positively in online communication than in face-to-face communication, whereas negative cues, such as disconfirming feedback, are likely to be interpreted as more negative. With respect to effects on self-esteem, we therefore hypothesize that the effects of confirming and disconfirming feedback are stronger in online communication compared to face-to-face communication ( $\mathrm{H} 1 \mathrm{~b})$.

\section{Dynamics of Reciprocal Exchange in Online Communication}

Several traditional disclosure theories, such as social exchange theory (Altman \& Taylor, 1973) and Jourard's (1964) theory of self-disclosure, deal with the dynamics of self-disclosure in face-to-face communication. These theories all emphasize that self-disclosure involves the exchange of personal information. During the exchange of personal information, the reciprocity principle plays an important role (Jourard, 1964): The intimacy of disclosure by one communication partner leads to similarly intimate disclosure by the other. Sharing of impersonal/superficial information elicits impersonal/superficial responses, whereas more personal disclosures garner more personal responses. Most importantly, in the case of intimate self-disclosure, mutual disclosure increases liking between communication partners and the intimacy of their relationship (Collins \& Miller, 1994).

Self-disclosure theories as well as the hyperpersonal communication model thus explain how the beneficial effects of self-disclosure on interpersonal relationships take place through reciprocal responses between communication partners. Importantly, these theories suggest that messages can have substantial consequences partly through others' behavior in response to these messages. We argue that the same mechanisms may also apply to the effects of evaluative feedback messages on the self-esteem of the receiver. That is, the effect of online feedback on self-esteem may take place indirectly through the reciprocal feedback.

The effect of feedback on the receiver's reciprocal feedback. In addition to its role in people's tendency to reciprocate the level of intimacy in each other's messages (Jourard, 1964), the reciprocity principle also plays an important role in determining people's positive and negative behavior in response to others (Fehr \& Gächter, 2000). In response to friendly actions by others, people tend to behave in a positive way (e.g., by being nice and cooperative), whereas they are more negative in response to other's hostile actions (Fehr \& Gächter, 2000). 
Previous studies have repeatedly shown reciprocity effects in a variety of contexts and behaviors (e.g., Cialdini \& James, 2009; Giacalone \& Greenberg, 1997; Tidd \& Lockard, 1978), which suggests that similar effects are also likely to occur with respect to the valence of interpersonal communication. More specifically, people are likely to reciprocate the valence of their communication partners' messages by responding in a positive way to a positive message and in a negative way to a negative message. With respect to positive (i.e., confirming) and negative (i.e., disconfirming) feedback, this suggests that people may respond to confirming feedback by giving confirming or positive feedback of their own, but respond to disconfirming feedback by returning disconfirming or negative feedback. Based on terminology in research on reciprocity (i.e., positive reciprocity and negative reciprocity; Fehr \& Gächter, 2000), we call these positive feedback responses to received feedback messages positive reciprocal feedback, and we term the negative feedback responses negative reciprocal feedback. We hypothesize that receiving confirming feedback leads to more positive reciprocal feedback, whereas disconfirming feedback leads to more negative reciprocal feedback $(\mathrm{H} 2 \mathrm{a})$.

While the valence of the feedback that people receive may determine the valence of their response to this feedback, the communication mode in which the conversation takes place may affect the intensity of their response. The reduced audiovisual cues and higher controllability of online communication allow people to be more deliberate in their expression of interpersonal affect, without undermining the message through uncontrolled, equivocal nonverbal behaviors (Walther, 1996). As a consequence, they feel more comfortable showing their "true" self (Bargh, McKenna, \& Fitzsimons, 2002). In line with the previously demonstrated positive effects of increased online self-disclosure on relationships (e.g., Jiang et al., 2011; Valkenburg \& Peter, 2009a), attributions arising in online communication lead people to more intense positive thoughts and feelings compared to face-to-face communication. Previous research has indeed indicated a higher proportion of explicit expressions of positive (as well as negative) regard in online communication compared to face-to-face communication (Kiesler, Zubrow, Moses, \& Geller, 1985). In sum, existing literature suggests that online communication may intensify both positive and negative responses to feedback compared to face-to-face communication. Therefore, we hypothesize that the effects of confirming and disconfirming feedback on the valence of the receiver's reciprocal feedback are stronger in online communication compared to face-to-face communication ( $\mathrm{H} 2 \mathrm{~b})$.

The effect of reciprocal feedback on self-esteem. Based on the important role of reciprocal exchanges in online communication effects proposed by the hyperpersonal communication models (e.g., Kiesler, Siegel, \& McGuire, 1984; Suler, 2004), the communication mode may not only affect how one responds to feedback, but also how this response, in turn, affects self-esteem. Literature on how people's online responses may affect their self-esteem is scarce. However, based on two theoretical considerations, different processes may take place, which may lead to different effects of reciprocal feedback for people's self-esteem.

Firstly, according to the self-perception theory, people infer how they feel based on their behavior (Bem, 1972). More specifically, people form their attitudes, in part, after seeing their own behavior. For instance, arguing in favor of an opinion has been shown to lead to attitude change in the direction of this opinion, even if one originally opposed this opinion (Chaiken \& Baldwin, 1981). Similar effects have been found in online communication (Walther, Van Der Heide, Tong, Carr, \& Atkin, 2010). Based on this research, it is thus likely that positive behavior, such as providing positive reciprocal feedback to a communication partner, induces positive self-perceptions and increases self-esteem. In contrast, negative behavior, such as giving negative reciprocal feedback, is likely to induce negative self-perceptions and decrease one's self-esteem.

Another process with which reciprocal feedback can influence self-esteem is through retaliation. Retaliation is a way of coping with unfavorable treatment by another person (e.g., Gollwitzer \& Denzler, 2009), in particular when one's self-esteem has been damaged (Bies, Tripp, \& Kramer, 1997). In such a case, people may be motivated to respond negatively in return to disconfirming feedback from a communication partner, for instance by giving negative reciprocal feedback to this person. As research has shown, such retaliation can restore equity (i.e., a perception of fairness) in a relationship (Berscheid, Boye, \& Walster, 1968) and may restore or even improve self-esteem. However, being negative to others may also have negative consequences for self-esteem. For example, scholars have suggested that retaliation may make people ruminate more about the situation instead of taking their mind of it (Carlsmith, Wilson, \& Gilbert, 2008). In addition, because being negative to others is generally seen as socially undesirable behavior, this may feel awkward, which in turn might cancel out 
the positive effect of retaliation on self-esteem. Because both theoretical explanations seem equally plausible, we did not pose a hypothesis concerning the effect of the reciprocal feedback on self-esteem. Instead, we investigate the following research question: What is the effect of the valence of the reciprocal feedback on selfesteem (RQ1).

In both theoretical explanations for the effect of reciprocal feedback, communication mode may play a crucial role. For instance, the intensity of the self-presentation effect may be stronger in online communication compared to face-to-face communication. In online communication, people typically can see their messages persistently on the screen, which can magnify the effects of their behavior on their self-perceptions. In addition, the hyperpersonal communication model suggest that online communication provides a mutually reinforcing feedback loop, which intensifies positive interpretation of positive cues (Walther, 1996). That is, an initial positive message, such as confirming feedback, may trigger a positive loop in the conversation, which may ultimately have a greater impact on self-esteem in online communication than in face-to-face communication. Also in the case of retaliation, in online communication, people's lowered inhibition makes it easier to respond with negative reciprocal feedback to a communication partner. Based on these theoretical considerations we hypothesize that the effect of reciprocal feedback on self-esteem is stronger in online communication compared to the face-to-face communication (H3).

\section{Method}

We conducted an experiment with a two (communication mode: online vs. face-to-face) by two (feedback valence: confirming vs. disconfirming) between-subjects design. Participants were randomly assigned to one of the four conditions: (1) online confirming feedback, (2) online disconfirming feedback, (3) face-to-face confirming feedback, (4) face-to-face disconfirming feedback. Feedback was given to the participant by a confederate pretending to participate in the experiment.

\section{Participants}

The data were collected from September to November of 2013. Of the 154 participants who took part in the experiment, five were excluded because they exceeded the age limit of 30 years old. We chose participants younger than 30 years of age to prevent that age difference between the participants and the confederates (who were both in their early twenties) was too large and would interfere with the credibility of the confederates and their feedback. The final sample consisted of 149 participants $(51.7 \%$ female), with a mean age of 22.0 years old $(S D=3.0)$. Most participants were students of higher education $(92.6 \%)$, were born in the Netherlands $(94.0 \%)$, and had parents who were also born in the Netherlands (mother $79.9 \%$, father $80.5 \%$ ).

\section{Procedure}

The study was approved by the department's ethical committee. Participants were recruited at the university campus and through an ad on the student webpage. Prospective participants were told that the study investigated how people get to know each other. Participants received a monetary reward for their participation (face-to-face conditions: 5 Euro for 30 minutes; online conditions: 10 Euro for 1 hour $^{1}$ ). Students could also choose to participate in exchange for course credits.

Participants were paired with a confederate of the same sex. Upon arrival at the laboratory, participants received a general instruction of the procedure of the experiment and filled in the consent forms. Participants were told that they would do a get-to-know-you task with another person (the confederate), in which they would have a short conversation, give first impressions of each other, and complete short questionnaires. They were told that this study was a first step in the process of getting acquainted, and that they would be invited for a follow-up study to get to know each other further. The communication mode in which the conversation between the participant and the confederate took place was either face-to-face or online (i.e., instant messaging). Both the participant and the confederate received a booklet that included all instructions about the task as well as the paper-and-pencil questionnaires. In all conditions, participants were instructed to start with the first step in the booklet after the experimenter had left the room. 
During the experiment, the participants first engaged in deep self-disclosure to the confederate. The participant answered 12 questions, which were asked by the confederate in a fixed order. Confederates were instructed to react to the participants' answers in a neutral way, for example by saying: "I see" or "OK. Next question." After the self-disclosure, the confederate gave feedback as an apparent first impression based on the self-disclosure of the participant. After receiving this feedback, participants completed a questionnaire measuring their state self-esteem. Then, the participants and confederate exchanged roles: Participants asked the confederate the same questions, and gave feedback to the confederate. Afterwards, participants completed a questionnaire, which again measured their state self-esteem, as well as demographic information (i.e., date of birth, birth country, birth country of mother and father, sexual orientation, their studies). Finally, participants were probed for suspicion, thanked, and immediately debriefed. The experimenter explained the role of the confederate and that the feedback the participants had received was not real, and that there would not be a follow-up conversation.

Self-disclosure. The questions used to induce self-disclosure among the participants were inspired by Taylor and Altman's (1966) set of intimacy-scaled stimuli. The topics of the questions were based on items that were originally used to measure self-disclosure (Jourard \& Lasakow, 1958; Miller, Berg, \& Archer, 1983; Rubin \& Shenker, 1978), manipulate intimacy of self-disclosure (Archer, Berg, \& Runge, 1980) and relational closeness (Aron, Melinat, Aron, Vallone, \& Bator, 1997; Sedikides, Campbell, Reader, \& Elliot, 1999), used as topics for selfpresentation (Gonzales \& Hancock, 2008; Walther, 2011; Walther et al., 2011) and complemented with new items. We pre-tested a list of superficial and deep questions among undergraduate students, who indicated how superficial or intimate they found each question on a scale from 1 (very superficial) to 9 (very intimate). We selected the items with the highest (i.e., most intimate) and lowest (i.e., most superficial) scores that scored exclusively on the intended side of the scale (i.e., lower or higher than the neutral score 5). After some adaptations, a final version of the questions was created, which started with a few introductory, relatively superficial topics (e.g., the participants' hobbies) and continued with deeper topics. Examples of deep selfdisclosure questions are: "What are negative aspects of your personality?", "What is the best experience you have ever had?", and "What is something you worry about or have ever worried about?"

Manipulation of communication mode. To manipulate communication mode, participants communicated with the confederate online or face-to-face. In the face-to-face conditions, the conversations took place in a living-room type of laboratory. In the online conditions, the conversations took place on computers in the lab through a chat room on Chatzy.com. The participant was seated behind a desk with a laptop in the living room laboratory, while the confederate was in a different room, also with a computer. Participants were instructed to fill in their first name as a screen name in the chat program. The confederates also used their first names. After creating a screen name, participants could start chatting with the confederate.

Participants in the face-to-face conditions met the confederate at the entrance of the laboratory, whereas the participants in the online conditions did not meet the confederate until after the experiment. However, participants in all conditions had or received the same information about the "other participant" before the conversation, that is, his/her first name and sex. In the face-to-face conditions, the confederate also filled in all questionnaires in the booklet, whereas this was not necessary in the online conditions because the participant could not see the confederate. With the consent of the participants, the face-to-face conversations were audiotaped and the chat logs were saved.

Manipulation of valence of feedback. To manipulate valence of feedback, the confederate gave confirming or disconfirming feedback to the participant in the form of a first impression of the participant. This operationalization was based on Cissna and Sieburg's (1981) conceptualization of confirmation and disconfirmation. Before the data collection, the researchers and confederates practiced the feedback, to ensure that it was experienced as clearly confirming or disconfirming, in particular with respect to two aspects: awareness of the other's significance or worth, and a (possible) relationship or affiliation with the other. The confirming feedback was: "My first impression... good, I guess. The things you like to do appeal to me. And based on the things you say about yourself, about your personality and stuff, you seem, at first glance, to be someone I would become friends with. Yes, I got a positive impression of you." The disconfirming feedback was: "My first impression... I'm not sure. The things you like to do are not really what I like to do. And based on the things you say about yourself, about your personality and stuff, you seem, at first glance, to be someone I would probably 
not become friends with. Unfortunately, I didn't get a positive impression of you. I'm sorry, but I want to be honest with you."

\section{Measures}

State self-esteem. State self-esteem was assessed using an adapted version of a global self-worth scale (Harter, 2012b), consisting of five items: "At this moment..." (1) "I am pretty pleased with myself," (2) "I like the way I am leading my life," (3) "I am happy with myself," (4) "I like the kind of person I am," (5) "I am very happy being the way I am." Participants responded using a Visual Analogue Scale (VAS) whereby they drew a vertical line on a horizontal line of $100 \mathrm{~mm}$, with the left end point $(0 \mathrm{~mm})$ representing "not at all" and the right endpoint $(100$ $\mathrm{mm}$ ) "very much". The distance between the right endpoint and the vertical line, represent their response. We created a scale based on the average of the five individual items. State-self-esteem was measured two times during the experiment, after receiving feedback from the confederate (Time 1), and after giving feedback to the confederate (Time 2). Based on the measures at these two times points, we created two scales: state self-esteem at Time $1(\alpha=.90, M=70.58, S D=13.76)$ and state self-esteem at Time $2(a=.94, M=73.03, S D=13.81)$.

Valence of participant's reciprocal feedback. The valence of the face-to-face and online feedback by the participant were coded by the first author. Coding categories were: 1 (negative), 2, (somewhat negative), 3 (neutral), 4 (somewhat positive), and 5 (positive). An example of positive reciprocal feedback that was provided is: "My impression of you is good. You are an open person and you are honest about your doubts. You seem like an interesting person to get to know more". An example of negative reciprocal feedback that was provided is: "My first impression of you is not good. I think you have a weak attitude in life and you need to grow up. Good luck with that!". To assess intra-coder reliability, 10\% $(n=16)$ of the cases were coded a second time after 10 months. Krippendorff's alpha showed good intra-coder reliability $(a=.89)$. To establish inter-coding reliability, a second coder was trained, who coded about $10 \%$ of the items $(n=16)$. Krippendorff's alpha showed sufficient intercoder reliability $(\alpha=.73)$. The mean valence of the reciprocal feedback was $4(S D=1.04$, range $=1-5)$.

Demographic variables. Information was collected concerning participants' sex, age (i.e., date of birth), country of birth, as well as country of birth of their mother and father, sexual orientation, and their study (open questions).

\section{Results}

\section{Randomization Check and Probing for Suspicion}

Before investigating the hypotheses, we tested whether the four conditions differed with respect to participants' sex and age. Univariate analyses of variance (ANOVA) did not show any significant differences between the four conditions with regard to $\operatorname{sex}(F(3,149)=0.04, p=.989)$, and age $(F(3,144)=0.26, p=.854)$, showing that randomization was successful.

Out of 149 participants, 20 reported suspecting what the study was about. Univariate analyses revealed that suspicion did not affect self-esteem at Time $1(F(1,149)=0.61, p=.438)$, self-esteem at Time $2(F(1,149)=0.61, p$ $=.432)$ or the valence of the reciprocal feedback $(F(13,149)=2.63, p=.105)$.

\section{Effects of Mode and Feedback on Self-Esteem}

Hypothesis 1a predicted that receiving confirming feedback to one's self-disclosure would lead to higher selfesteem compared to receiving disconfirming feedback. An analysis of variance (ANOVA) with self-esteem at Time 1 as the dependent variable and feedback valence and communication mode as independent variables revealed no direct effect of feedback valence on self-esteem $(F(1,145)=0.00, p=.960)$. Hypothesis 1 a was thus not supported. Likewise, there was no effect of communication mode (online vs. offline) on self-esteem $(F(1,145)=$ $0.27, p=.605)$. 
Hypothesis $1 \mathrm{~b}$ predicted that the effects of confirming and disconfirming feedback would be stronger in online communication compared to face-to-face communication. To test this, a second ANOVA examined self-esteem at Time 1 as the dependent variable for main effects of feedback valence and communication mode, and for the interaction between feedback valence and communication mode. The results did not show a significant interaction effect between feedback and mode $(F(1,144)=0.08, p=.777)$. Hypothesis $1 \mathrm{~b}$ was also not supported.

\section{Effects of Mode and Feedback on Participants' Reciprocal Feedback}

Hypothesis $2 a$ predicted that receiving confirming feedback would lead to more positive reciprocal feedback, whereas disconfirming feedback would lead to more negative reciprocal feedback. An ANOVA with the participant's reciprocal feedback as a dependent variable and feedback valence and communication mode as independent variables showed main effects of communication mode and feedback valence on the valence of the participants' reciprocal feedback. Participants gave more positive reciprocal feedback in face-to-face communication $(M=4.36, S D=0.83)$ than in online communication $(M=3.65, S D=1.12), F(1,143)=25.20, p<$ .001. In addition, receiving confirming feedback resulted in giving more positive reciprocal feedback $(M=4.67, S D$ $=0.61)$ compared to receiving disconfirming feedback $(M=3.35, S D=0.97), F(1,143)=104.30, p<.001$. This result supported Hypothesis $2 \mathrm{a}$.

Hypothesis $2 \mathrm{~b}$ stated that the effect of feedback valence on the participant's reciprocal feedback valence would be stronger in online communication compared to face-to-face communication. We conducted an ANOVA with the reciprocal feedback as a dependent variable for the effects of feedback valence, communication mode, and the interaction between feedback valence and communication mode. Results showed a significant difference in the level of positivity in the feedback that participants gave to the confederate in both communication modes. However, this difference was larger in the online communication mode compared to the offline mode. In the online conditions, participants responded with more negative feedback when confederates had provided disconfirming feedback to them $(M=2.95, S D=0.88)$, and gave more positive feedback when they had received confirming feedback $(M=4.47, S D=0.75)$. However, this was less distinct in the face-to-face condition, where participants tended to offer more positive feedback in response to the confederate's feedback, regardless of whether the confederate had given confirming $(M=4.84, S D=0.37)$ or disconfirming feedback $(M=3.82, S D=$ 0.87). This disparity created a significant interaction effect between the valence of the feedback received from the confederate and the communication mode, $F(1,142)=4.15, p=.044$ (see Figure 1). Participants in online conditions were more negative in response to disconfirming feedback compared to face-to-face conditions, but not more positive after receiving confirming feedback. Hypothesis $2 b$ was thus partially supported.

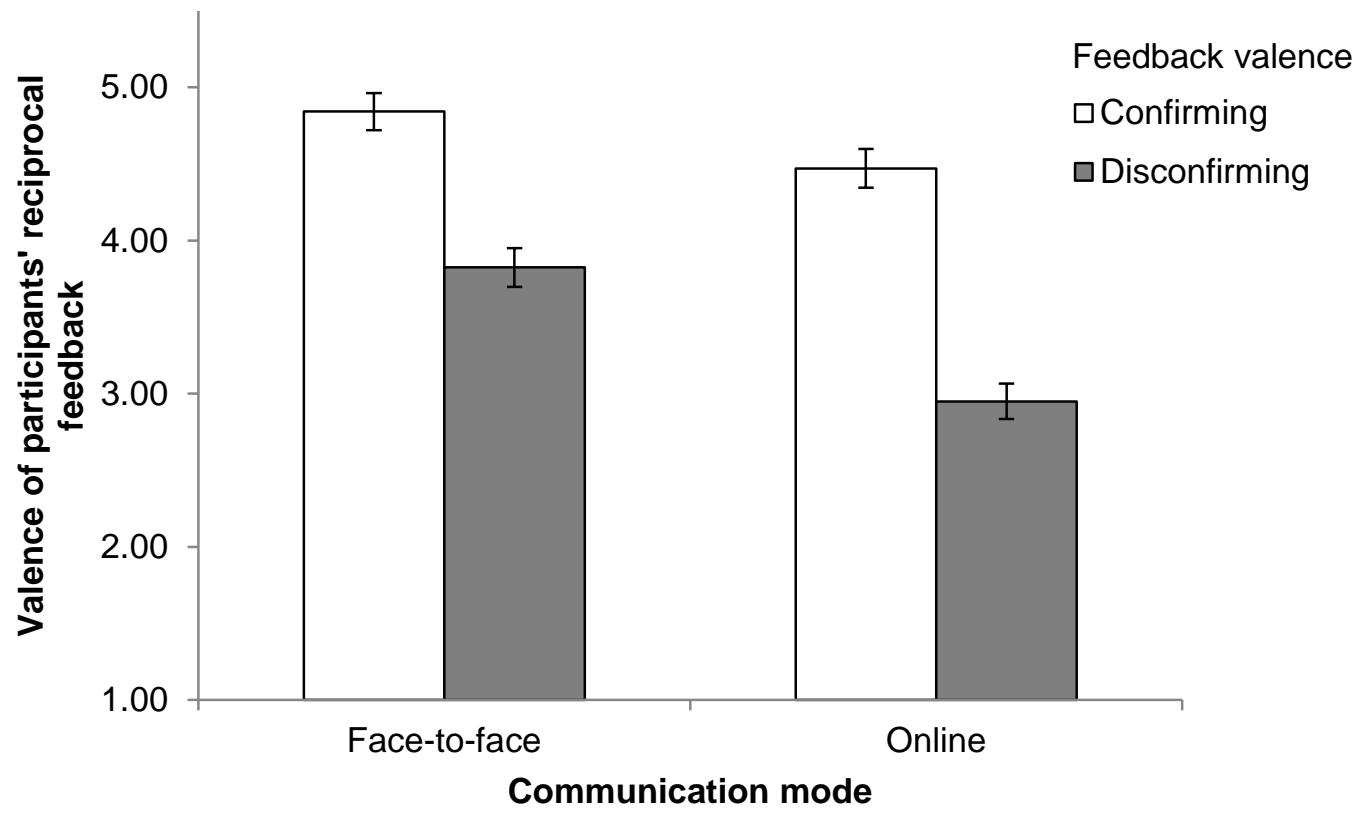

Figure 1. Interaction effect between feedback valence and communication mode on valence of participants' reciprocal feedback. 
Our research question concerned the effect of the valence of the reciprocal feedback on self-esteem (RQ1). Furthermore, we hypothesized that this effect would be stronger in online compared to face-to-face communication (H3). A regression analysis examined self-esteem at Time 2 as the dependent variable, with the communication mode and participants' reciprocal feedback as the independent variables, while controlling for self-esteem at Time 1. No main effect of feedback emerged: The valence of the reciprocal feedback did not affect participants' self-esteem at Time $2, B=-0.71, S E=0.52, p=.179$. Likewise, the communication mode had no main effect on self-esteem at Time $2, B=0.24, S E=1.09, p=.829$. The level of self-esteem after receiving feedback (Time 1) was positively related to self-esteem after giving feedback (Time 2), $B=0.90, S E=0.04, p<.001$.

To investigate whether the effect of reciprocal feedback on self-esteem differed by the communication mode (H3), we conducted a regression analysis using Hayes' (2013) SPSS PROCESS macro (model 1), with self-esteem at Time 2 as the dependent variable, and the communication mode, the reciprocal feedback, and the interaction between the reciprocal feedback and communication mode as independent variables. Self-esteem at Time 1 functioned as a covariate. An interaction effect between the reciprocal feedback and communication mode revealed that communication mode moderated the effect of reciprocal feedback on self-esteem at Time $2, B=$ $2.35, S E=1.08, p=.032$ (see Figure 2). In order to see whether the slopes for the two communication modes were significant, we tested the conditional effects (i.e., simple slopes) of reciprocal feedback on self-esteem, separately for the face-to-face conditions and for the online conditions. Results showed that, in online communication, giving more negative reciprocal feedback significantly improved individuals' self-esteem compared to giving positive reciprocal feedback, $B=-1.52, S E=0.64, p=.019$. In contrast, the effect of valence of the reciprocal feedback on self-esteem was not significant in face-to-face communication, $B=0.83, S E=0.88, p=$ .344. The Johnson-Neymann technique demonstrated that the difference between online and offline communication was significant only for reciprocal feedback with a negative valence (i.e. scores below 3 ). H3 was thus supported.

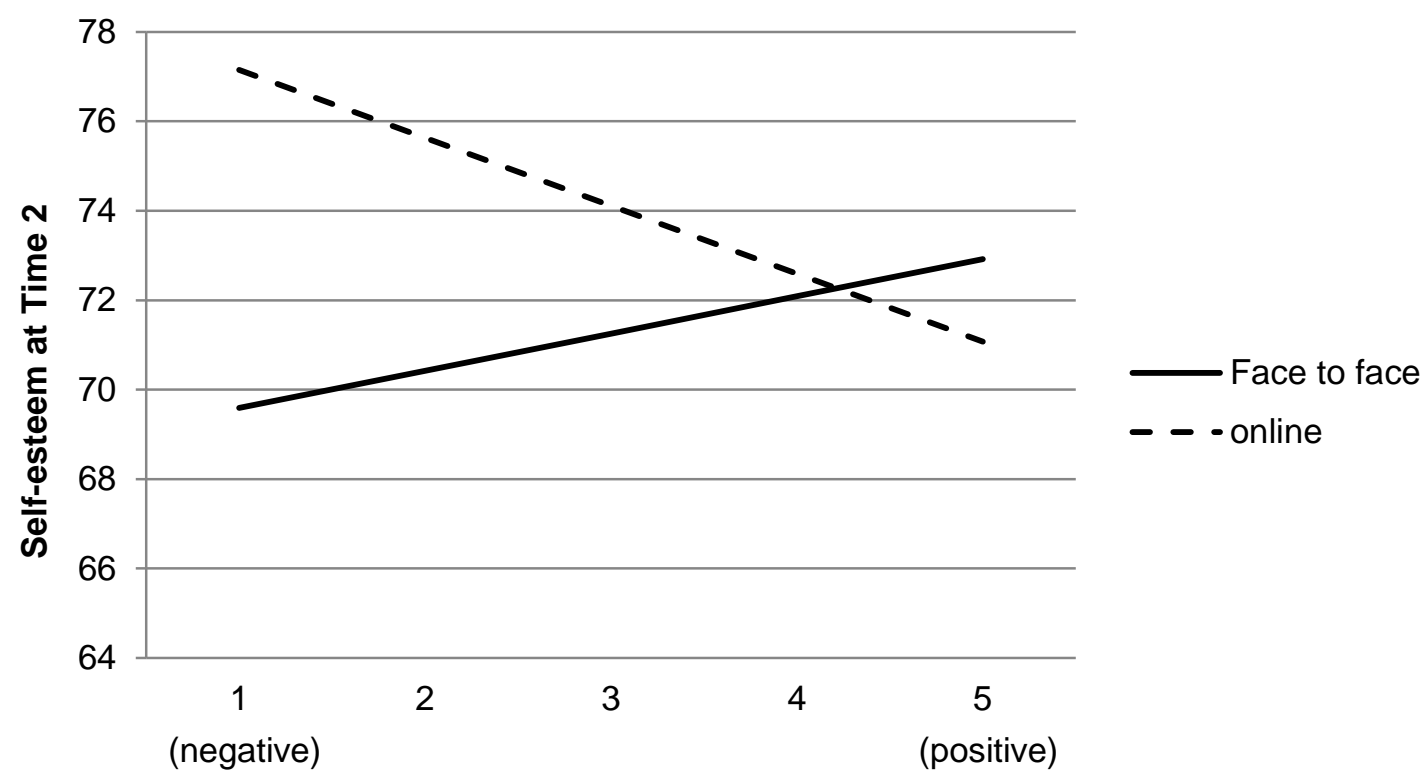

Figure 2. Interaction effect between participant's reciprocal feedback valence and communication mode on self-esteem at Time 2, corrected for self-esteem at Time 1.

\section{Moderated Mediation Model}

Since the abovementioned analyses revealed an effect of receiving feedback on providing feedback (i.e. reciprocal feedback) and that providing feedback subsequently influenced participants' self-esteem, we wanted to test for a possible indirect effect. Therefore, as a follow-up, we investigated whether the valence of the feedback of the confederate had an indirect effect on the participants' self-esteem through the reciprocal 
feedback and whether this indirect effect was different for online and face-to-face communications (i.e. moderated mediation, see Figure 3). To test moderated mediation we used a regression analysis using Hayes' (2013) SPSS PROCESS macro (model 58). In this model, self-esteem at Time 2 was included as the outcome variable, feedback of the confederate as the predictor and valence of the reciprocal feedback as the mediator. In addition, communication mode was included as the moderator. Finally, self-esteem at Time 1 was included as a covariate. As such, we tested whether feedback indirectly influenced self-esteem, via reciprocal feedback and whether this indirect effect was different in online versus face-to-face communication. The effect of feedback valence on self-esteem at Time 2 in online communication was significantly mediated by the reciprocal feedback based on parametric significance testing (i.e. effect is significant when 0 is outside the confidence interval), $B=$ $2.45, S E=1.30,95 \% B C I[0.24,5.20]$. This was not the case for face-to-face communication, $B=-0.77, S E=1.40$, $95 \% B C l[-4.14,1.63]$. This suggests that in the online condition feedback influenced self-esteem through its influence on reciprocal feedback.

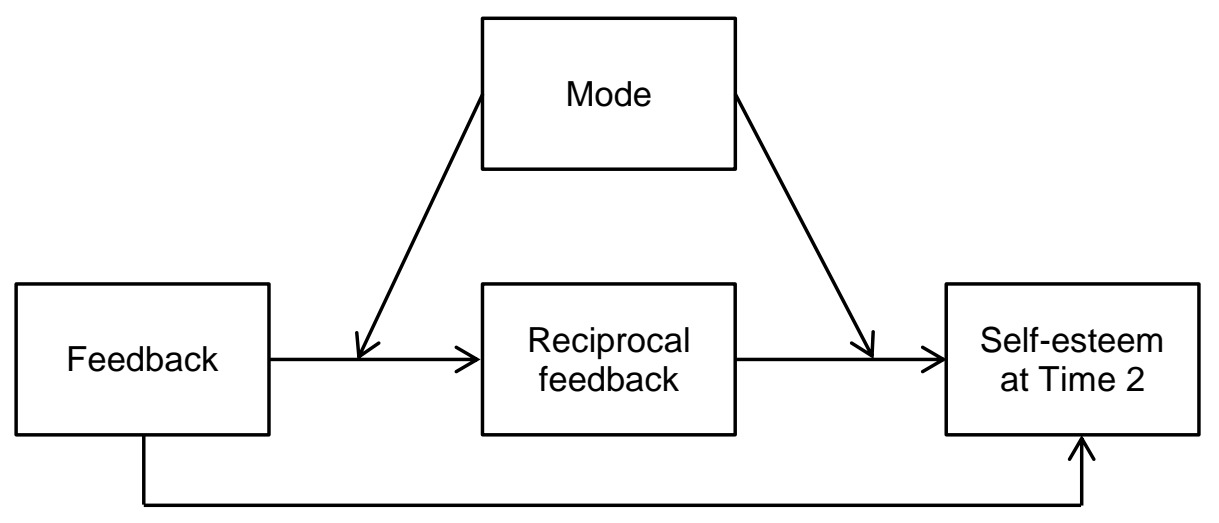

Figure 3. The mediated moderation model of the indirect effect of feedback valence on self-esteem at Time 2 through the reciprocal feedback valence, moderated by communication mode.

\section{Discussion}

The first aim of the current study was to investigate the effect of online feedback on self-esteem after disclosing oneself to a communication partner. The second aim was to then examine the role of reciprocal feedback in this relationship. The third and final aim was to investigate whether these effects differed between online and faceto-face communication. Results showed that, although the valence of feedback did not immediately affect selfesteem, it indirectly influenced self-esteem through the reciprocal feedback. This indirect effect was moderated by the communication mode: In online communication, participants responded with more negative reciprocal feedback to disconfirming feedback than in face-to-face communication, which positively affected their selfesteem in online communication, but not in face-to-face communication.

\section{The Effect of Online Feedback on Self-Esteem}

Our finding that the valence of the feedback did not affect the self-esteem of the participant after receiving this feedback is inconsistent with our expectations and with earlier results. This contradictory result may be due to differences in the operationalization of feedback. Earlier studies investigated feedback on adolescents' social network site profiles, which included feedback from several peers (Thomaes et al., 2010; Valkenburg et al., 2006), or a more general measure of the frequency of positive and negative comments on adolescents' profiles (Thomaes et al., 2010). In contrast, the current study looked at the effect of single feedback messages. In addition, the participant did not know the confederate before the experiment. While we suggested that the participant and confederate would meet again in a follow up, it might still mean that there was not a lot at stake for the participant. Perhaps this is why self-esteem was not influenced directly after the feedback. Taken all together, it is plausible that repeated feedback messages and feedback from multiple (familiar) communication partners on self-disclosure is necessary to influence the receiver's self-esteem. 
Also in contrast to our expectations, the mode of the conversation (online vs. face-to- face) did not moderate the effect of receiving confirming or disconfirming feedback on one's self-esteem. We thus did not find the intensifying influence of online communication on the interpretation of cues as proposed by the hyperpersonal communication model (Walther, 1996). One explanation for this unexpected finding may be our focus on an initial stage of getting acquainted, where individuals are analyzing common interests to decide whether to maintain a relationship (i.e. experimentation stage; Knapp, 1978). Perhaps in a later stage (i.e., intensifying stage; Knapp 1987), when there have been several exchanges and the communication becomes less formal and intensifies, will the differences between online and face-to-face communication become more apparent.

\section{The Effect of Feedback on the Receiver's Reciprocal Feedback}

In line with the important role of the reciprocity principle in people's behavior (e.g., Fehr \& Gächter, 2000), we found that participants generally reacted more positively to confirming feedback from their communication partner than to disconfirming feedback. However, whereas we expected that online communication would intensify both positive and negative responses, only negative responses (to disconfirming feedback) were intensified online. This suggests that online communication may differentially affect an individual's willingness to respond to another person, depending on whether this response is negative or positive.

One possible explanation may be that people are particularly motivated to retaliate if others have treated them badly, resulting in a more intense response to other people's negative actions than to positive actions (e.g., Baumeister, Bratslavsky, Finkenauer, \& Vohs, 2001). Disconfirming feedback is a sign of social rejection, and thus more threatening to one's self-esteem (Harter, 2012a; Leary, Tambor, Terdal, \& Downs, 1995), which may generate a stronger motivation to deal with this type of feedback. Importantly, the current study suggests that characteristics of online communication seem to facilitate doing so. In the online conversations, participants may have felt less inhibited, but also safer from their communication partner's possible negative response, and were consequently more likely to retaliate by providing negative reciprocal feedback. In the face-to-face communication, by contrast, the riskiness of responding negatively may have formed an obstacle against retaliating.

Participants' less negative responses to face-to-face disconfirming feedback compared to online disconfirming feedback may also be due to the tendency to express negativity through nonverbal behavior in face-to-face encounters. Because online communication partners are forced to use the available cues to express the same message valence, they are more verbally explicit in providing negative responses (Walther, Loh, \& Granka, 2005). It is possible that people express similar levels of negativity in their responses to feedback in online and face-toface communication when taking into account their nonverbal behavior. In order to further investigate differences between online communication and face-to-face communication with respect to the particular cues (i.e., verbal and nonverbal) people use to express negative information, future research should also include visual data (i.e., videotapes) of conversations to analyze the nonverbal behavior in people's responses to feedback.

\section{The Effect of Reciprocal Feedback on Self-Esteem}

The valence of reciprocal feedback only affected participants' self-esteem in the online conditions. The results of the current study particularly support the predictions based on online disinhibition and retaliation processes: Online communication facilitates a disinhibition-induced opportunity for retaliation. Being able to respond negatively to disconfirming feedback from a communication partner helps restore one's self-esteem. Participants may have perceived their own negative response as a sign of assertiveness, which boosted their self-esteem.

These results also seem to support the idea that a negative spiral effect may be more likely in online communication. Albeit in a relatively short interaction, online communication induced more negative responses to disconfirming feedback than did face-to-face communication. If the conversation had allowed more exchanges between communication partners, this could likely have led to mutual negative responses. This supports the hypothesis that the visual anonymity in online communication may loosen someone's sense of what is appropriate behavior (Konrath, 2012) and lead to deindividuation (i.e., a state of decreased self- 
evaluation causing antinormative and disinhibited behavior; Diener, 1980). This might explain current problems with hate-speech, cyberbullying, and general incivility on online platforms such as Facebook and Twitter (Middaugh, Bowyer, \& Kahne, 2017).

\section{Online Feedback Dynamics in Online Communication}

Our study contributes to existing research in two ways. First, the present study points to an important role of people's responses in the effects of online feedback on self-esteem. Our findings suggest the occurrence of coping behavior through retaliation, and possibly an initial stage of a negative spiral effect, in online communication. Importantly, the effect of a communication partner's evaluative feedback on people's selfesteem seems to take shape only as people reciprocate feedback to their communication partner. Second, the current study shows that people in face-to-face and online communication may respond differently with respect to expressing negativity to others. Although there is much evidence of more negative messages online than offline (e.g., Kiesler et al., 1985; Orengo Castellá, Zornoza Abad, Prieto Alonso, \& Peiró Silla, 2000; Siegel, Dubrovsky, Kiesler, \& McGuire, 1986), it rarely been investigated whether online communicators express negativity automatically or purposefully. Our results suggest that people use online communication to express negativity in a purposeful way. Retaliating to disconfirming feedback is less risky in online communication than in face-to-face communication. Our participants seem not to retaliate automatically to disconfirming feedback, but only when they felt relatively safe (i.e., in online communication). Research has generally shown that online communication facilitates giving negative feedback (e.g., Kiesler et al., 1985; Orengo Castellá et al., 2000; Siegel et al., 1986). Our study adds to this by suggesting that online communication users may be less susceptible to selfdenigration as a result of providing negative responses to received negative feedback.

\section{Limitations and Directions for Future Research}

One limitation of the current research is that the feedback provided by the confederate was very general in order to fit the self-disclosure of all participants. As such, this feedback might be different and less 'natural' than the feedback people receive in daily life. This together with the fact that the confederate and the participants were unacquainted might have influenced our results. While investigating the effects of feedback in longitudinal surveys has also proven to be challenging (Valkenburg et al., 2017) using a more naturalistic environment, to study how receiving feedback online influences self-esteem, is warranted. In addition, factors such as liking of the sender of feedback should than also be taken into account as this is known to influence self-disclosure (Collins \& Miller, 1994).

Another limitation is that in this experiment the confirming or disconfirming feedback was provided only once. A possible extension of the current study could be to investigate the influence of repeated feedback over time. It is still an open question whether the effects of feedback increase over time and after more exchanges between communication partners, whether they fade off or whether they can be reduced, for example by retaliating to negative feedback.

In addition, it is important to know the consequences of feedback to people's self-disclosure or self-presentation over time, as well as how people cope with, or respond to, this feedback. Peer feedback (i.e., peer acceptance or rejection) forms an important determinant of self-esteem and well-being of young people. Because a great part of their social lives takes place through online communication on social network sites, the effects of online feedback are particularly relevant to young people's psychosocial development and well-being.

Finally, future research may focus more strongly on individual differences. People interpret information differently based on individual characteristics (e.g., social anxiety; Amin, Foa, \& Coles, 1998). In online environments, less information is available, so the interpretation of information is probably more dependent on characteristics that influence how individuals interpret information based on selective cues. This is particularly interesting with respect to ambiguous feedback, where the interpretation of this feedback plays a more important role. 


\section{Note}

1. The duration of the online condition was longer than the face-to-face condition because typing takes more time than talking.

\section{References}

Altman, I., \& Taylor, D. A. (1973). Social penetration: The development of interpersonal relationships. New York, NY: Holt, Rinehart \& Winston.

Amin, N., Foa, E. B., \& Coles, M. E. (1998). Negative interpretation bias in social phobia. Behaviour Research and Therapy, 36, 945-957. https://doi.org/10.1016/S0005-7967(98)00060-6

Antheunis, M. L., Valkenburg, P. M., \& Peter, J. (2007). Computer-mediated communication and interpersonal attraction: An experimental test of two explanatory hypotheses. CyberPsychology and Behavior, 10, 831-836. https://doi.org/10.1089/cpb.2007.9945

Archer, R. L., Berg, J. H., \& Runge, T. E. (1980). Active and passive observers' attraction to a self-disclosing other. Journal of Experimental Social Psychology, 16, 130-145. https://doi.org/10.1016/0022-1031(80)90004-9

Aron, A., Melinat, E., Aron, E. N., Vallone, R. D., \& Bator, R. J. (1997). The experimental generation of interpersonal closeness: A procedure and some preliminary findings. Personality and Social Psychology Bulletin, 23, 363-377. https://doi.org/10.1177/0146167297234003

Bargh, J. A., McKenna, K. Y. A., \& Fitzsimons, G. M. (2002). Can you see the real me? Activation and expression of the "true self" on the Internet. Journal of Social Issues, 58, 33-48. https://doi.org/10.1111/1540-4560.00247

Baumeister, R. F., Bratslavsky, E., Finkenauer, C., \& Vohs, K. D. (2001). Bad is stronger than good. Review of General Psychology, 5, 323-370. https://doi.org/10.1037//1089-2680.5.4.323

Baumeister, R.F., Campbell, J.D., Krueger, J.I., \& Vohs, K.D. (2003). Does high self-esteem cause better performance, interpersonal success, happiness, or healthier lifestyles? Psychological Science in Public Interest, 4, 144. https://doi.org/10.1111/1529-1006.01431

Bazarova, N. N. (2012). Public intimacy: Disclosure interpretation and social judgments on Facebook. Journal of Communication, 62, 815-832. https://doi.org/10.1111/j.1460-2466.2012.01664.x

Bem, D. J. (1972). Self-perception theory. Advances in Experimental Social Psychology, 6, 1-62. https://doi.org/10.1016/s0065-2601(08)60024-6

Berscheid, E., Boye, D., \& Walster, E. (1968). Retaliation as a means of restoring equity. Journal of Personality and Social Psychology, 10, 370-376. https://doi.org/10.1037/h0026817

Bies, R. J., Tripp, T. M., \& Kramer, R. M. (Eds.). (1997). At the breaking point: Cognitive and social dynamics of revenge in organizations. Thousand Oaks, CA: SAGE Publications.

Birnie, C., \& Holmberg, D. (2007). But what will they say? The impact of receiving feedback on women's relationship narratives. Narrative Inquiry, 17, 231-258. https://doi.org/10.1075/ni.17.2.05bir

Carlsmith, K. M., Wilson, T. D., \& Gilbert, D. T. (2008). The paradoxical consequences of revenge. Journal of Personality and Social Psychology, 95, 1316-1324. https://doi.org/10.1037/a0012165 
Carr, C. T., \& Foreman, A. C. (2016). Identity shift III: Effects of publicness of feedback and relational closeness in computer-mediated communication. Media Psychology, 19, 334-358.

https://doi.org/10.1080/15213269.2015.1049276

Chaiken, S., \& Baldwin, M. W. (1981). Affective-cognitive consistency and the effect of salient behavioral information on the self-perception of attitudes. Journal of Personality and Social Psychology, 41, 1-12.

https://doi.org/10.1037/0022-3514.41.1.1

Cialdini, R. B., \& James, L. (2009). Influence: Science and practice (Vol. 4). Boston, MA: Pearson Education.

Cissna, K. N., \& Sieburg, E. (1981). Patterns of interactional confirmation and disconfirmation. In C. Wilder-Mott \& J. H. Weakland (Eds.), Rigor and imagination: Essays from the legacy of Gregory Bateson (pp. 253-282). New York, NY: Praeger.

Collins, N. L., \& Miller, L. C. (1994). Self-disclosure and liking: A meta-analytic review. Psychological Bulletin, 116, 457-475. https://doi.org/10.1037/0033-2909.116.3.457

Diener, E. (1980). Deindividuation: The absence of self-awareness and selfregulation in group members. In P. Paulus (Ed.), The psychology of group influence (pp. 209-242). Hillsdale, NJ: Erlbaum.

Fehr, E., \& Gächter, S. (2000). Fairness and retaliation: The economics of reciprocity. Journal of Economic Perspectives, 14, 159-181. https://doi.org/10.1257/jep.14.3.159

Giacalone, R. A., \& Greenberg, J. (1997). Antisocial behavior in organizations. Thousand Oaks, CA: SAGE Publications.

Gollwitzer, M., \& Denzler, M. (2009). What makes revenge sweet: Seeing the offender suffer or delivering a message? Journal of Experimental Social Psychology, 45, 840-844. https://doi.org/10.1016/j.jesp.2009.03.001

Gonzales, A. L., \& Hancock, J. T. (2008). Identity shift in computer-mediated environments. Media Psychology, 11, 167-185. https://doi.org/10.1080/15213260802023433

Gonzales, A. L. (2014). Text-based communication influences self-esteem more than face-to-face or cellphone communication. Computers in Human Behavior, 39, 197-203. https://doi.org/10.1016/j.chb.2014.07.026

Greitemeyer, T., Mügge, D. O., \& Bollermann, I. (2014). Having responsive Facebook friends affects the satisfaction of psychological needs more than having many Facebook friends. Basic and Applied Social Psychology, 36, 252-258. https://doi.org/0.1080/01973533.2014.900619

Gruenenfelder-Steiger, A. E., Harris, M. A., \& Fend, H. A. (2016). Subjective and objective peer approval evaluations and self-esteem development: A test of reciprocal, prospective, and long-term effects. Developmental Psychology, 52, 1563-1577. https://doi.org/10.1037/dev0000147

Harter, S. (2012a). The construction of the self: A developmental perspective (2nd ed.). New York, NY: Guilford Press.

Harter, S. (2012b). Manual for the self-perception profile for adolescents. Denver, CO: University of Denver.

Hayes, A. F. (2013). Introduction to mediation, moderation, and conditional process analysis: A regression-based approach. New York, NY: Guilford Press.

Jiang, L. C., Bazarova, N. N., \& Hancock, J. T. (2011). The disclosure-intimacy link in computer-mediated communication: An attributional extension of the hyperpersonal model. Human Communication Research, 37, 5877. https://doi.org/10.1111/j.1468-2958.2010.01393.x

Jourard, S. M. (1964). The transparent self: Self-disclosure and well-being. New York, NY: Van Nostrand Reinhold. 
Jourard, S. M., \& Lasakow, P. (1958). Some factors in self-disclosure. The Journal of Abnormal and Social Psychology, 56, 91-98. https://doi.org/10.1037/h0043357

Kiesler, S., Siegel, J., \& McGuire, T. W. (1984). Social psychological effects of computer-mediated communication. American Psychologist, 39, 1123-1134. https://doi.org/10.1037/0003-066X.39.10.1123

Kiesler, S., Zubrow, D., Moses, A., \& Geller, V. (1985). Affect in computer-mediated communication: An experiment in synchronous terminal-to-terminal discussion. Human-Computer Interaction, 1, 77-104. https://doi.org/10.1207/s15327051hci0101_3

Knapp, M. L. (1978) Social intercourse: From greeting to goodbye. Needham Heights, MA: Allyn \& Bacon.

Konrath, S. (2012). The empathy paradox: Increasing disconnection in the age of increasing connection. In R. Luppicini (Ed.), Handbook of research on technoself: Identity in a technological society (pp. 204-228). IGI Global.

Kruger, J., Epley, N., Parker, J., \& Ng, Z.-W. (2005). Egocentrism over e-mail: Can we communicate as well as we think? Journal of Personality and Social Psychology, 89, 925-936. https://doi.org/10.1037/0022-3514.89.6.925

Leary, M. R., Tambor, E. S., Terdal, S. K., \& Downs, D. L. (1995). Self-esteem as an interpersonal monitor: The sociometer hypothesis. Journal of Personality and Social Psychology, 68, 518-530.

https://doi.org/10.1080/1047840X.2003.9682891

Middaugh, E., Bowyer, B., \& Kahne, J. (2017). U suk! Participatory media and youth experiences with political discourse. Youth \& Society, 49, 902-922. https://doi.org/10.1177/0044118×16655246

Miller, L. C., Berg, J. H., \& Archer, R. L. (1983). Openers: Individuals who elicit intimate self-disclosure. Journal of Personality and Social Psychology, 44, 1234-1244. https://doi.org/10.1037/0022-3514.44.6.1234

Miura, A., \& Yamashita, K. (2007). Psychological and social influences on blog writing: An online survey of blog authors in Japan. Journal of Computer-Mediated Communication, 12, 1452-1471. https://doi.org/10.1111/j.10836101.2007.00381.x

Orengo Castellá, V., Zornoza Abad, A. M., Prieto Alonso, F., \& Peiró Silla, J. M. (2000). The influence of familiarity among group members, group atmosphere and assertiveness on uninhibited behavior through three different communication media. Computers in Human Behavior, 16, 141-159. https://doi.org/10.1016/S0747-

5632(00)00012-1

Reis, H. T., \& Shaver, P. (1988). Intimacy as an interpersonal process. In S. Duck, D. F. Hay, S. E. Hobfoll, W. Ickes, \& B. M. Montgomery (Eds.), Handbook of personal relationships: Theory, research and interventions (pp. 367-389). Oxford, UK: John Wiley \& Sons.

Rubin, Z., \& Shenker, S. (1978). Friendship, proximity, and self-disclosure. Journal of Personality, 46, 1-22. https://doi.org/10.1111/j.1467-6494.1978.tb00599.x

Sedikides, C., Campbell, W. K., Reader, G., \& Elliot, A. J. (1999). The relationship closeness induction task. Representative Research in Social Psychology, 23, 1-4.

Siegel, J., Dubrovsky, V., Kiesler, S., \& McGuire, T. W. (1986). Group processes in computer-mediated communication. Organizational Behavior and Human Decision Processes, 37, 157-187.

https://doi.org/10.1016/0749-5978(86)90050-6

Snyder, M., Tanke, E. D., \& Berscheid, E. (1977). Social perception and interpersonal behavior: On the selffulfilling nature of social stereotypes. Journal of Personality and Social Psychology, 35, 656-666.

https://doi.org/10.1037/0022-3514.35.9.656 
Sowislo, J. F., \& Orth, U. (2013). Does low self-esteem predict depression and anxiety? A meta-analysis of longitudinal studies. Psychological Bulletin, 139, 213-240. http://dx.doi.org/10.1037/a0028931

Srivastava, S., \& Beer, J. S. (2005). How self-evaluations relate to being liked by others: Integrating sociometer and attachment perspectives. Journal of Personality and Social Psychology, 89, 966-977. https://doi.org/10.1037/00223514.89.6.966

Suler, J. (2004). The online disinhibition effect. CyberPsychology \& Behavior, 7, 321-326. https://doi.org/10.1089/1094931041291295

Taylor, D. A., \& Altman, I. (1966). Intimacy-scaled stimuli for use in studies of interpersonal relations. Psychological Reports, 19, 729-730. https://doi.org/10.2466/pr0.1966.19.3.729

Thomaes, S., Reijntjes, A., Orobio de Castro, B., Bushman, B. J., Poorthuis, A., \& Telch, M. J. (2010). I like me if you like me: On the interpersonal modulation and regulation of preadolescents' state self-esteem. Child Development, 81, 811-825. https://doi.org/10.1111/j.1467-8624.2010.01435.x

Tidd, K. L., \& Lockard, J. S. (1978). Monetary significance of the affiliative smile: A case for reciprocal altruism. Bulletin of the Psychonomic Society, 11, 344-346. https://doi.org/10.3758/bf03336849

Valkenburg, P. M., Koutamanis, M., Vossen, H.G.M. (2017). The concurrent and longitudinal relationships between adolescents' use of social network sites and their self-esteem. Computers in Human Behavior, 76, 35-41. https://doi.org/org/10.1016/j.chb.2017.07.008

Valkenburg, P. M., \& Peter, J. (2009a). The effects of instant messaging on the quality of adolescents' existing friendships: A longitudinal study. Journal of Communication, 59, 79-97. https://doi.org/10.1111/j.14602466.2008.01405.x

Valkenburg, P. M., \& Peter, J. (2009b). Social consequences of the Internet for adolescents: A decade of research. Current Directions in Psychological Science, 18, 1-5. https://doi.org/10.1111/j.1467-8721.2009.01595.x

Valkenburg, P. M., Peter, J., \& Schouten, A. P. (2006). Friend networking sites and their relationship to adolescents' well-being and social-esteem. CyberPsychology \& Behavior, 9, 585-590.

https://doi.org/10.1089/cpb.2006.9.584

Walther, J. B. (1996). Computer-mediated communication: Impersonal, interpersonal, and hyperpersonal interaction. Communication Research, 23, 3-43. https://doi.org/10.1177/009365096023001001

Walther, J. B. (2011). Theories of computer-mediated communication and interpersonal relations. In M. L. Knapp \& J. A. Daly (Eds.), The handbook of interpersonal communication (4th ed., pp. 443-479). Thousand Oaks, CA: SAGE Publications.

Walther, J. B., DeAndrea, D. C., \& Tong, S. T. (2010). Computer-mediated communication versus vocal communication in the attenuation of preinteraction impressions. Media Psychology, 13, 364-386.

https://doi.org/10.1080/15213269.2010.524913

Walther, J. B., Kashian, N., Jang, J.-W., \& Shin, S. Y. (2016). Overattribution of liking in computer-mediated communication: Partners infer the results of their own influence as their partners' affection. Communication Research, 43, 372-390. https://doi.org/10.1177/0093650214565898

Walther, J. B., Liang, Y. J., DeAndrea, D. C., Tong, S. T., Carr, C. T., Spottswood, E. L., \& Amichai-Hamburger, Y. (2011). The effect of feedback on identity shift in computer-mediated communication. Media Psychology, 14, 1-26. https://doi.org/10.1080/15213269.2010.547832 
Walther, J. B., Loh, T., \& Granka, L. (2005). Let me count the ways: The interchange of verbal and nonverbal cues in computer-mediated and face-to-face affinity. Journal of Language and Social Psychology, 24, 36-65.

https://doi.org/10.1177/0261927X04273036

Walther, J. B., Van Der Heide, B., Tong, S. T., Carr, C. T., \& Atkin, C. K. (2010). Effects of interpersonal goals on inadvertent intrapersonal influence in computer-mediated communication. Human Communication Research, 36, 323-347. https://doi.org/10.1111/j.1468-2958.2010.01378.x

\title{
Correspondence to:
}

Helen Vossen

Department of Child and Adolescent Studies

Utrecht University

Heidelberglaan 1

3584 CS Utrecht

The Netherlands

E-mail address: h.g.m.vossen(at)uu.nl

Editorial record: First submission received on February 16, 2017. Revisions received on October 31, 2017, and December 18, 2017. Accepted for publication on December 20, 2017.

\begin{abstract}
About Authors
Dr. Helen Vossen is assistant professor at the department of Child and Adolescent Studies at Utrecht University. Her teaching as well as research focuses on the influence of media on the development of psychosocial problems in children and adolescents, as well as the role media plays within the family context.

Dr. Maria Koutamanis did her PhD at the Amsterdam School of Communication Research. Her dissertation focused on psychosocial consequences of adolescents' online behavior. Currently she is working as an illustrator and designer.

Joseph B. Walther is a Distinguished Professor in Communication, the Bertelesen Presidential Chair in Information Technology and Society, and the Director of the Center for Information Technology and Society at UCSB. His teaching and research focus on computer-mediated communication and social media in personal relationships, groups, educational settings, and inter-ethnic conflict, topics on which he has contributed several original theories and numerous experiments and surveys. Students interested in working on projects related to these topics should get in touch to explore possibilities.
\end{abstract}

